\title{
RESEARCH OF INFLUENTIAL CONSTRUCTIONAL PARAMETERS ON THE STABILITY OF THE FIXATOR SARAFIX
}

\author{
MESIC, E[Imedin]; PERVAN, N[edim]; REPCIC, N[edzad] \& MUMINOVIC, A[dil]
}

\begin{abstract}
This paper presents research results of influential constructional parameters on the stability of the Sarafix external fixation system, applied to a tibia, in case of unstable fracture. Experimental tests were performed under axial compression for three configurations of Sarafix fixator $(A, B$ and $C$ ), with two different interfragment distances (20 and 50

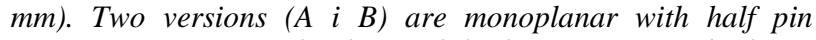
arrangement in a single plane, while the version $C$ is biplanar with half pin arrangement in a two plane. Values of bone segments displacements at the point of load and fracture gap have been analysed, based on which values of construct rigidity and fracture rigidity have been defined. Also, values of principal stresses generated on the fixator connecting rod have been controlled. Research of the load-bearings of half pin-bone connection (pull-out test) was aimed at determining the minimum value of force that will lead to pull a half pin from the cadaveric bone. Experimental testing has been performed on a universal material testing machine, using tensometer measuring equipment.

Keywords: the Sarafix external fracture fixation system / stability of fixator / interfragmentary displacements / principal stresses / experimental testing
\end{abstract}

\section{INTRODUCTION}

External fixator systems are medical devices for stabilization of bone fractures, and their compliance aims at producing an interfragmentary motion that promotes rapid and successful healing.

The aim of the fixation technique is anatomical reduction and immobilization of the bone segments, as well as maintenance of this anatomical stabilization concept throughout the treatment by external stiffening of the fracture gap separating the bone segments. This aim is achieved by an external frame that is connected percutaneously to the bone segments by pins or wires. During the war, the Sarafix found its highest application in the treatment of extensive gunshot-explosive fractures of long bones of the extremities. Today, in peacetime traumatology, it is used in accidental injury in traffic accidents and industrial trauma [1].

In recent years, increasingly using external fixators special purpose, axial-dynamic fixators and disposable fixators. Most of the structural solutions of fixators differ only in the differential geometric configuration details. Today, in war situations are used as simple, quick and easily applicable, stable fixators. They are usually disposable and made of high-tech materials.

Further development of the fixator is to improve the biomechanical capabilities, the economic aspect of the methods of external fixation and the use of new materials.

\section{OBJECTIVE AND METHODS}

All commercial fixators now in use passed a biomechanical study before their first application. However, as Sarafix emerged in situations of conflict, its biomechanical testing was not carried out in terms of exact evaluation of the fixator stability on the load which is exposed during the postoperative period of a patientös treatment. Complete studies of biomechanical stability of the fixator Sarafix were performed at the Faculty of Mechanical Engineering Sarajevo in the masterös thesis [2]. The main value for evaluation of mechanical stability of the external fixator is fixator stiffness. The value of stiffness is defined by loads of external fixator, which it exposed in the postoperative treatment.

This paper presents results of stiffness analysis of the most used configuration of the Sarafix external fixator in the case of an unstable tibial fracture. The influential structural parameters of Sarafix are stiffness of the fixator, values of the principal stresses at measuring points, and stress generated in contact of one-half pinbone. Geometric parameters such as distance which defines the position of one-half pins and their numbers also have an impact on these structural parameters.

a)

b)

c)

Fig. 1.Sarafix fixator: a) configuration $\mathrm{A}, \mathrm{b}$ ) configuration $\mathrm{B}$, c) configuration $\mathrm{C}$

Tests were performed on three structural configurations of fixator Sarafix (A, B and C) with two different interfragmentary distances $(20$ and $50 \mathrm{~mm})$ (Fig. 1). The analyzed configurations of the Sarafix 
fixator were attached to proximal and distal tibia bone segment modeled with cylindrical wooden models with the known physical properties.

During the axial compression testing, the bone models were supported on ball joints, while maximal axial loading force applied to the proximal bone model was $F p=600 \mathrm{~N}$, under load control at the rate of $2 \mathrm{~N} / \mathrm{s}$. Experimental testing of the Sarafix fixator configuration under axial compression was carried out on the universal material testing machine (Zwick GmbH \& Co., Ulm, Germany, model 143501) using supports for holding of bone models (Fig. 2).

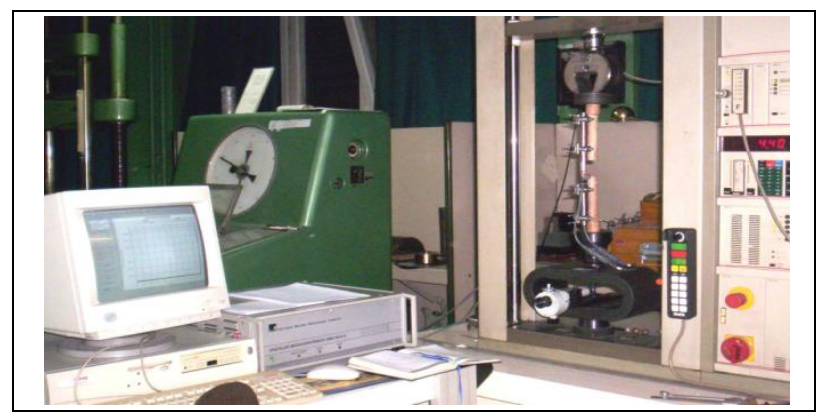

Fig. 2.Experimental testing on axial compression with tensometric measurement equipment

The following equipment from the HBM (Hottinger Baldwin Messtechnik GmbH, Darmstadt, Germany) manufacturer was used (Fig. 3):

a. digital measuring amplifier system $\tilde{n}$ digitales messverstarker-system (DMC) 9012A,

b. computer with software for acquisition, monitoring and processing of measurement results ñ Catman, and

c. four strain gauges (type 3/120LY11) connected in two Wheatstone half-bridges.

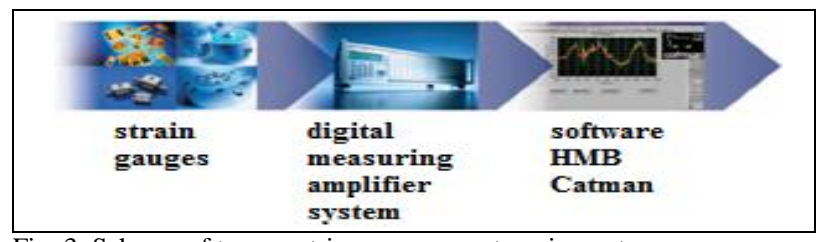

Fig. 3. Scheme of tensometric measurement equipment

The strain gauges were placed on the opposite sides of the Sarafix fixator connecting rod at the same locations where intensities of maximum and minimum principal stresses were monitored during the FEA. Thereafter, the strain gauges were connected with the DMC system and computer through two separate channels. In this way, the maximum and minimum principal strains on the measuring points were measured independently. This measurement method was applied because the connecting rod was subjected to a compound strain, which consisted of bending strain and axial compressive strain [4].

\section{EXPERIMENTAL TESTING ON AXIAL COMPRESSION}

During the experimental testing, strain gauges on the upper side $(\mathrm{SG}+)$ registered a total deformation of a positive sign - elongation (Ü), while the strain gauges on the underside (SG-) registered a total deformation of a negative sign - shortening (Üß) (Fig. 5) .
The strain, registered by Wheatstone half-bridge with active (SG+ and SG-) and compensation strain gauge (SGc+ and SGc-), is given by the relation [3]:

$$
\varepsilon=\frac{4}{k} \cdot \frac{U_{A}}{U_{E}}
$$

where: $k \tilde{n}$ is gauge factor, $U_{A} \tilde{\mathrm{n}}$ bridge output voltage,

$U_{E} \tilde{\mathbf{n}}$ excitation voltage (bridge input).

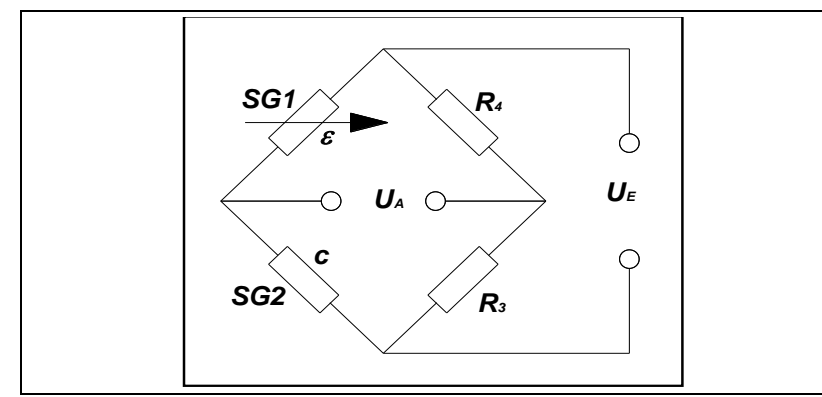

Fig. 4. Wheatstone half-bridge

Compensating strain gauges are used to compensate the effect of temperature on the measurement and they are of the same type as the active ones. In this way, it is possible to determine the intensity of the dominant principal stresses at the measuring points.

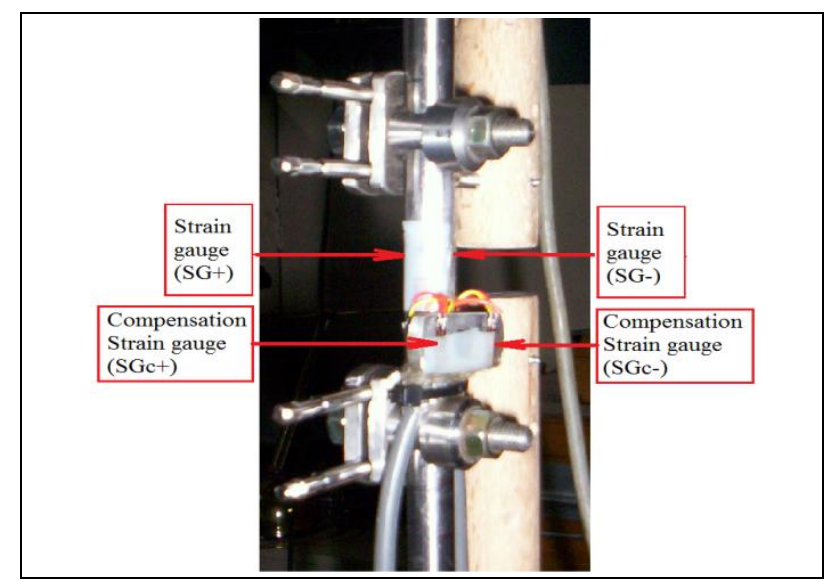

Fig. 5. Arrangement of strain gauges on connecting rod

Diagram of the axial displacement at the point of load in the loading phase is denoted by continuous lines (filled symbols along a line), while the unloading phase (unfilled symbols along a line) by discontinuous lines (Fig. 6 i 7). Hysteresis loops of compression are noticed on the diagrams of the axial displacement. Size of the hysteresis loop is significantly lower for versions B and $\mathrm{C}$ as compared to version $\mathrm{A}$, which indicates the occurrence of major slip in the contact surfaces in case of version A. The spontaneous capability of relaxation of the $\mathrm{B}$ and $\mathrm{C}$ Sarafix fixator configuration in the measuring range was 97,6\%. (Exfix - 95\%) [6].

Based on values of axial displacements at the point of load and axial load (Fp), values of construct stiffness of the fixator configuration have been determined.

$$
C_{P}=\frac{F_{P}}{\delta_{P}}\left(\frac{N}{m m}\right)
$$


where: $F_{P} \tilde{\mathrm{n}}$ is the applied axial loading force, $\delta_{P} \tilde{\mathrm{n}}$ is the axial displacement of proximal segment at the point of load

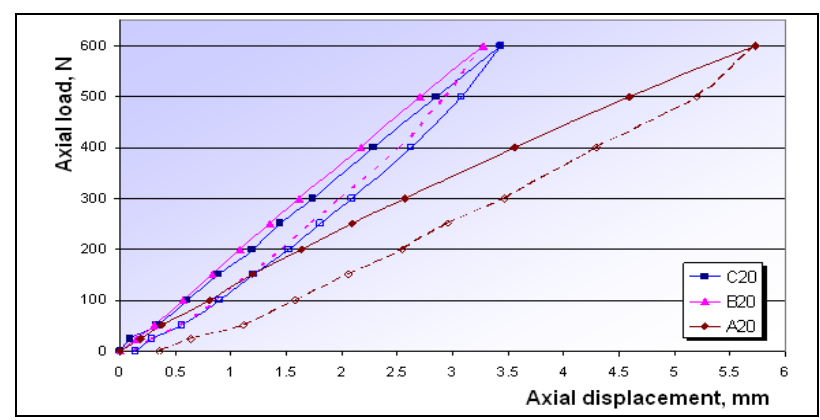

Fig. 6. Diagram of the axial displacement at the point of load (interfragmentary distance $20 \mathrm{~mm}$ )

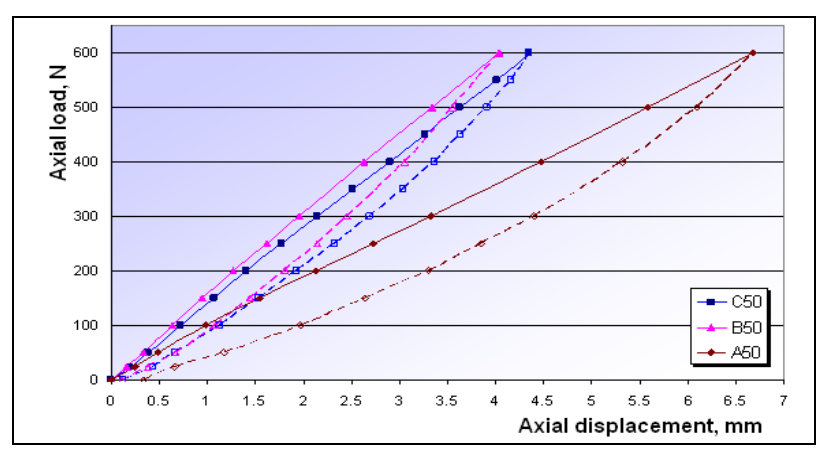

Fig. 7. Diagram of the axial displacement at the point of load (interfragmentary distance $50 \mathrm{~mm}$ )

Figures 8 and 9 shows the values of the principal stresses at measuring points for two interfragmentary distance (20 and 50mm). Strain gauges (SG-), which is closer to the bone segment, was registered a higher values of principal stresses in all fixator configurations. Strain gauges ( $\mathrm{SG}+$ ) was registered the highest principal stress $\left(\sigma_{1}\right)$ at the measuring point $\mathrm{MP}+$, while the strain gauges (SG-) was registered the lowest principal stress $\left(\sigma_{3}\right)$ at the measuring point MP-.

The principal stresses at the measuring points (MP+ and MP-) are determined through the relations:

$$
\begin{aligned}
& \sigma_{1}=\varepsilon_{1} E \\
& \sigma_{3}=\varepsilon_{3} E
\end{aligned}
$$

where:

$$
\begin{aligned}
& \varepsilon_{1}=-\varepsilon_{p}+\varepsilon_{s}=-\frac{F}{A E}+\frac{M}{E Z} \\
& \varepsilon_{3}=-\varepsilon_{p}-\varepsilon_{s}=-\frac{F}{A E}-\frac{M}{E Z}
\end{aligned}
$$

$\varepsilon_{p} \tilde{n}$ is the strain component caused by the axial

compressive force,

$\varepsilon_{s} \tilde{n}$ the strain component caused by the

bending moment,

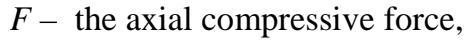

$A$ ñ the area cross-section of the fixator connecting rod,

$E \tilde{\text { n }}$ modulus of elasticity,

$M \tilde{n}$ bending moment,

$\mathrm{Z} \tilde{\mathrm{n}}$ section modulus of the fixator connecting rod.

Differences in values of the principal stresses at the measuring points of the analyzed version $\mathrm{A}$ and $\mathrm{B}$ are negligible (Fig. 8 i 9). Nevertheless, higher principal stress were registered in case of version A (Tab. 1).

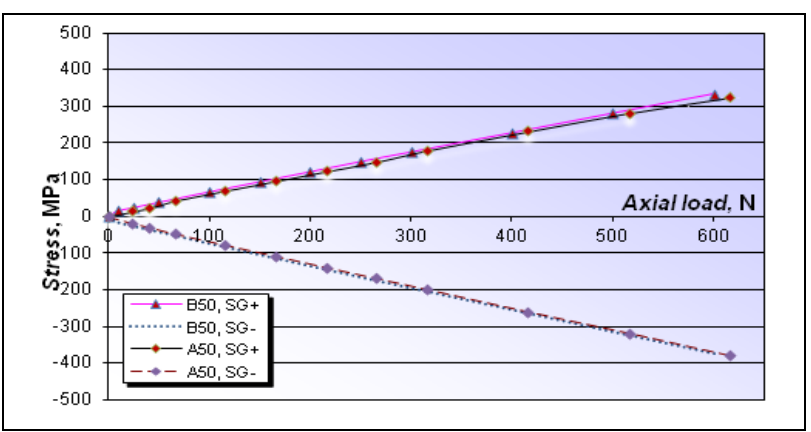

Fig. 8. Values of the principal stresses at measuring points (interfragmentary distance $50 \mathrm{~mm}$ )

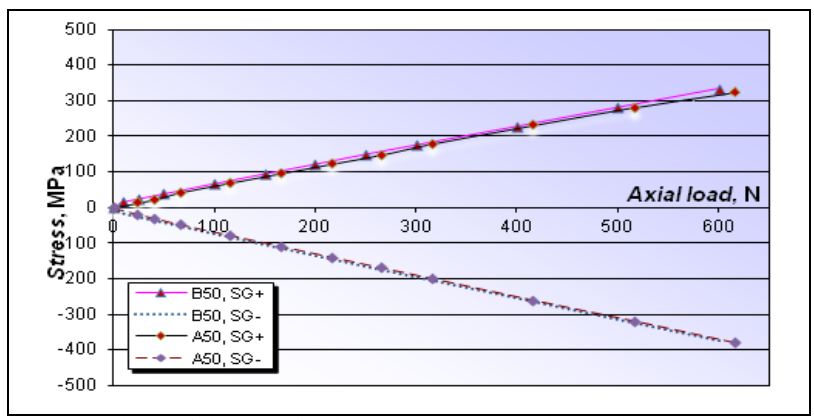

Fig. 9. Values of the principal stresses at measuring points (interfragmentary distance $20 \mathrm{~mm}$ )

\section{PULL-OUT TEST}

Pull-out test was performed at the Laboratory for biomechanical testing at Imperial College in London [1]. One of the aspects of biomechanical testing in vitro is the pull-out test, which is performed on cadaveric bone. Research of the load-bearings of half pin-bone connection (pull-out test) was aimed at determining the minimum value of force that will lead to pull a half pin from the cadaveric bone.

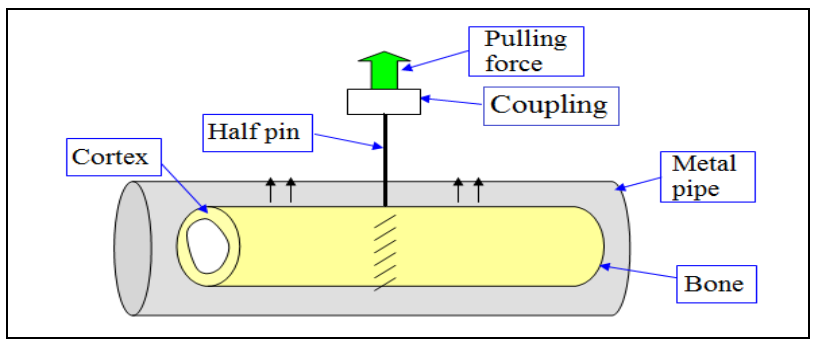

Fig. 10. Principle of pull-out test

Cadaveric bone is placed in a pierced metal pipe, which is fixed to the bench of test machine type Instron 5565. One of the half pin was screwed into the bone in the middle of its length, through the hole in the pipe, and then half pin was drawn with a coupling, which was attached to the movable part of the testing machine. (Fig. $10)$. During the tests, were measured value of force and displacement, which leads to pull a half pin from the cadaveric bone. Rate of load increase was $5 \mathrm{~mm} / \mathrm{min}$. The thickness of cortex at the place of half pin was 5,1 $\mathrm{mm}$. Testing was performed for two cases:

a. half pin was screwed through one cortex,

b. half pin was screwed through both cortex. 
Figure 11 shows results of pull-out test. In the initial phase of load connections for small loads, there are large displacements. This is explained by the establishment of appropriate contacts between the bandage of half pin and bone, which will enable the further transmission of load. Extraction half pin from tibia, in case of screwing through one cortex, was performed at a load of $3922 \mathrm{~N}$. In case of screwing through both cortex was performed at a load of $4443 \mathrm{~N}$.

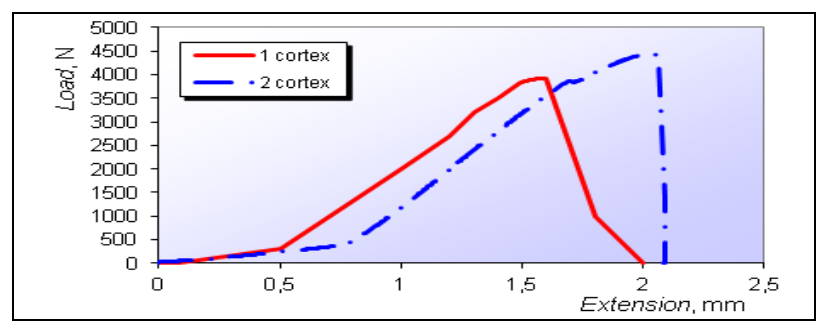

Fig. 11. Results of pull-out test

The difference in load between these two cases is 521 N. It is important to note that the research [7] on the cadaveric tibia bones, was recorded average value of force $3500 \mathrm{~N}$ for the half pin diameter $5 \mathrm{~mm}$.

\section{RESULTS}

The presented results of experimental testing on axial compression shows that the most important parameter for the construct stiffness is the number of half pins. The construct stiffness of the B20 Sarafix fixator configuration (with eight half pins) is greater for $75 \%$ than A20 (with four half pins).

Another important parameter for the construct stiffness is interfragmentary distance. The influence of interfragmentary distance on the construct stiffness of the $\mathrm{B}$ and C Sarafix fixator configuration is similar.

\begin{tabular}{|c|c|c|c|c|}
\hline \multirow{2}{*}{$\begin{array}{l}\text { Config. } \\
\text { of fixator }\end{array}$} & \multirow{2}{*}{$\begin{array}{c}\text { Max. axial } \\
\text { displacement } \\
\text { at the point of } \\
\text { load, } \\
\delta_{p}, \mathrm{~mm}\end{array}$} & \multirow{2}{*}{$\begin{array}{c}\text { Axial } \\
\text { const. } \\
\text { stiffness } \\
C_{p}, \mathbf{N} / \mathbf{m m}\end{array}$} & \multicolumn{2}{|c|}{$\begin{array}{c}\text { Principal stresses at } \\
\text { measuring points } \\
\text { (MPa) }\end{array}$} \\
\hline & & & $\sigma_{1}, \mathbf{M P}+$ & $\sigma_{3}$, MP- \\
\hline $\mathrm{C} 50$ & 4,35 & 137,93 & - & - \\
\hline $\mathrm{C} 20$ & 3,43 & 174,93 & - & - \\
\hline B50 & 4,04 & 148,51 & 334 & -374 \\
\hline B20 & 3,27 & 183,49 & 319 & -370 \\
\hline A50 & 6,69 & 89,69 & 326 & -379 \\
\hline A20 & 5,72 & 104,9 & 326 & -381 \\
\hline
\end{tabular}

Tab. 1. Values of structural parameters under maximum axial load

The construct stiffness of the C20 Sarafix fixator configuration is greater for $27 \%$ than $\mathrm{C} 50$, while the construct stiffness of the B20 Sarafix fixator configuration is greater for $24 \%$ than B50. Also, the position of half pins against the bending plane of connecting rod and fracture gap are important parameters. Configuration $\mathrm{B}$, in which a number of half pins placed closer to the bending plane and fracture gap, shows a higher axial construct stiffness than configuration $\mathrm{C}$. The construct stiffness of the B50 is greater for $8 \%$ than $\mathrm{C} 50$, while the construct stiffness of the $\mathrm{B} 20$ is greater for $5 \%$ than $\mathrm{C} 20$ (Tab. 1).

\section{CONCLUSION}

Analyzing the values of construct stiffness of the Sarafix fixator configuration, it can be said that versions
$\mathrm{B}$ and $\mathrm{C}$ have much higher values of construct stiffness than version A. Based on experimental testing of the Sarafix fixator configuration under axial compression, can determine influence of number and position of half pins and interfragmentary distance on the stability of fixator Sarafix.

The research showed that number of half pins is a parameter which is most influential factor on the construct stiffness, comparing version A (with four half pins) and version B (with eight half pins). The position of half pins against the bending plane of connecting rod is parameter which has a great influence on the construct stiffness, comparing version B (monoplanar arrangement of half pins) and $C$ (biplanar arrangement of half pins). Thus, the construct stiffness of the B20 is greater for 5\% than C20. Also, the size of interfragmentary distance is parameter which has a great influence on the construct stiffness. Thus, the construct stiffness of the C20 is greater for $27 \%$ than C50, the construct stiffness of the B20 is greater for $24 \%$ than B50, and the construct stiffness of the A20 is greater for $17 \%$ than A50.

Research has not been recorded important influence of analyzed parameters on the principal stresses generated at the measuring points. Number of half pins is parameter which exerted less influence on the values of these stresses.

Pull-out test was performed on cadaveric bone for two cases. In case when half pin was screwed through both cortex, showed that the load-bearings is greater for $13,3 \%$ than case when half pin was screwed through one cortex. For these reasons it is recommended that half pins screw through both cortex.

\section{REFERENCES}

[1] Dozic, S. (2011). Biomechanical characteristics of unilateral, biplanar fixator "Sarafix" in the treatment of extensive gunshotexplosive accidental fractures of long bones of the extremities, Ph.D. Dissertation, Faculty of Medicine Sarajevo, University of Sarajevo, Sarajevo, Bosnia and Herzegovina

[2] Mesic, E. (2008). Research of Mechanical Stability of the Sarafix External Fixation System, Post-graduation Thesis, Faculty of Mechanical Engineering Sarajevo, University of Sarajevo, Sarajevo, Bosnia and Herzegovina

[3] Basic, H. (2008). Mechanical Engineering Measurements, Faculty of Mechanical Engineering Sarajevo, ISBN 9958601230; 9789958601231, Sarajevo, Bosnia and Herzegovina

[4] Khan, A.S.; Wang, X. (2001). Strain Measurements and Stress Analysis, Prentice-Hall, ISBN 0130800767; 9780130800763, New Jersey, USA

[5] Mesic, E.; Muminovic, A.; Repcic, N.; Colic, M. (2010). Stiffness analysis of the Sarafix external fracture fixation system, Journal of Society for Development of Teaching and Business Processes, Technics Technologies Education Management-TTEM, Vol.5, No.1, April 2010, pp. 60-66, ISSN 1840-1503

[6] Exfix-catalogue, Orthoplant, Endoprothetik, Bremen, Germany.

[7] Remiger, A.R. (1992). Mechanical Properties of the Pinless External Fixator on Human Tibiae, The British Journal of Accident Surgery Injury, Vol.23, Suppl.3, pp. 28-42, ISSN 00201383

[8] Muminovic, A.; Mesic, E.; Repcic, N. (2007). Structural Analysis of Mechanical Characteristics of External Fixation Systems, $6^{\text {th }}$ International Scientific Conference on Production EngineeringRIM 2007, Development and Modernization of Production, Society for robotics, pp. 111-116., Bihal, Bosnia and Herzegovina

[9] Mesic, E.; Muminovic, A.; Repcic, N. (2009). Structural Analysis and Experimental Testing of External Fixator System Under Axial Compression, 13 ${ }^{\text {th }}$ International Research/Expert Conference, Trends in the Development of Machinery and Associated Technology-TMT 2009, pp. 497-500., Hammamet, Tunisia 